\title{
Correction to: Calibration of Genetic Algorithm Parameters for Mining-Related Optimization Problems
}

\author{
Martha E. Villalba Matamoros ${ }^{1}$ and Mustafa Kumral ${ }^{1,2}$
}

Correction to:

Natural Resources Research

https://doi.org/10.1007/s11053-018-9395-2

The original version of this article unfortunately contained a mistake in figures. The source file for figures was submitted and published incorrectly; hence, the figures should be swapped as given below.
Figure 3 in the published version must be Figure 4. Figure 4 in the published version must be Figure 6. Figure 5 in the published version must be Figure 3. Figure 6 in the published version must be Figure 5.

The correct figures with respect to their captions are presented with this erratum.

\footnotetext{
${ }^{1}$ Department of Mining and Materials Engineering, McGill University, 3450 University Street, Montreal QC H3A 0E8, Canada.

${ }^{2}$ To whom correspondence should be addressed; e-mail: mustafa.kumral@mcgill.ca
}

The original article can be found online at https://doi.org/10.1007/ s11053-018-9395-2. 


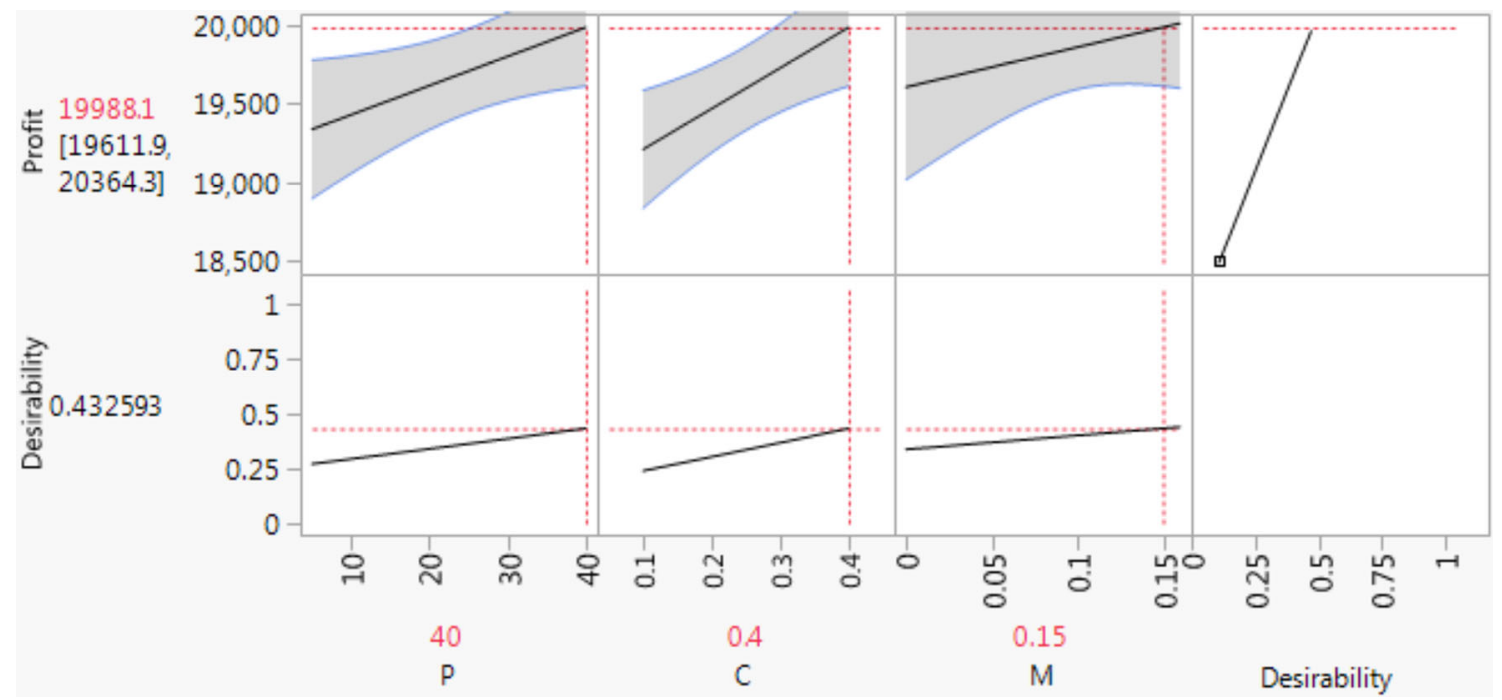

Figure 3. Prediction profiler and maximum desirability using the full factorial design.

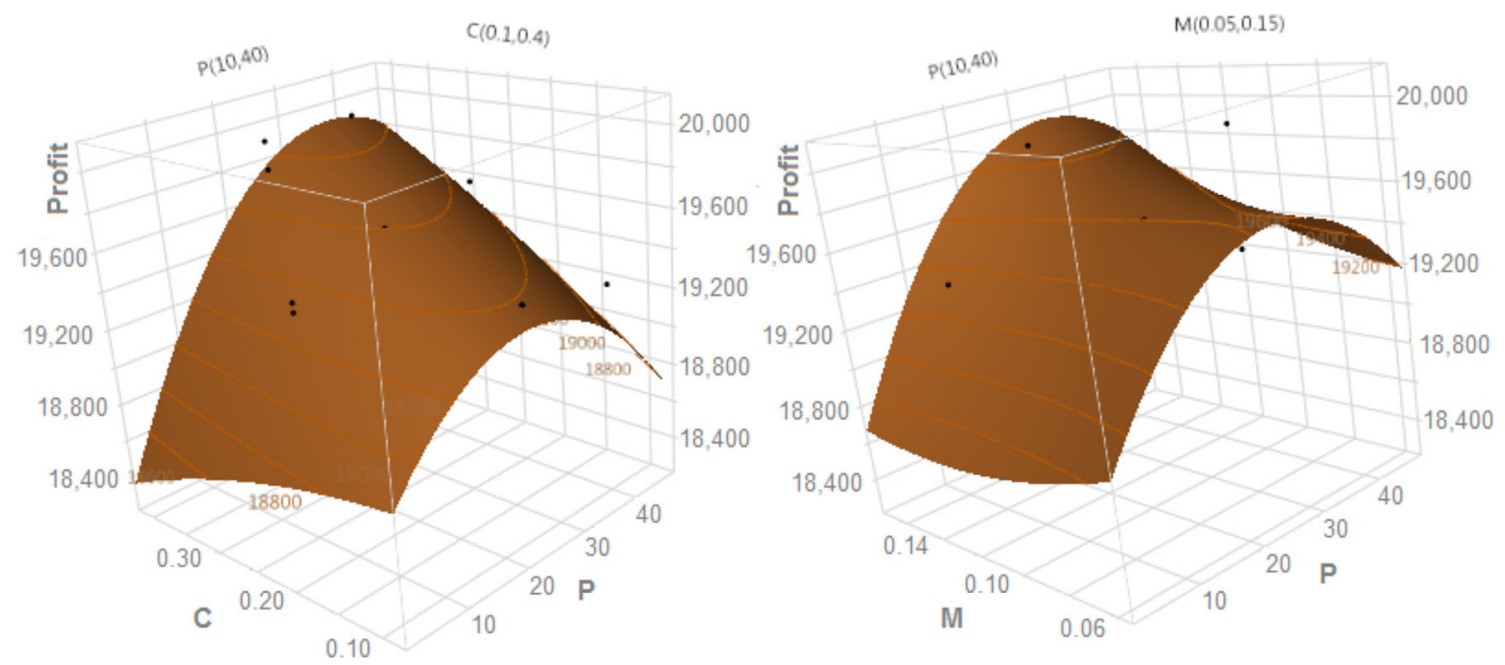

Figure 4. The surface of regression model using Box-Behnken design in RSM. 


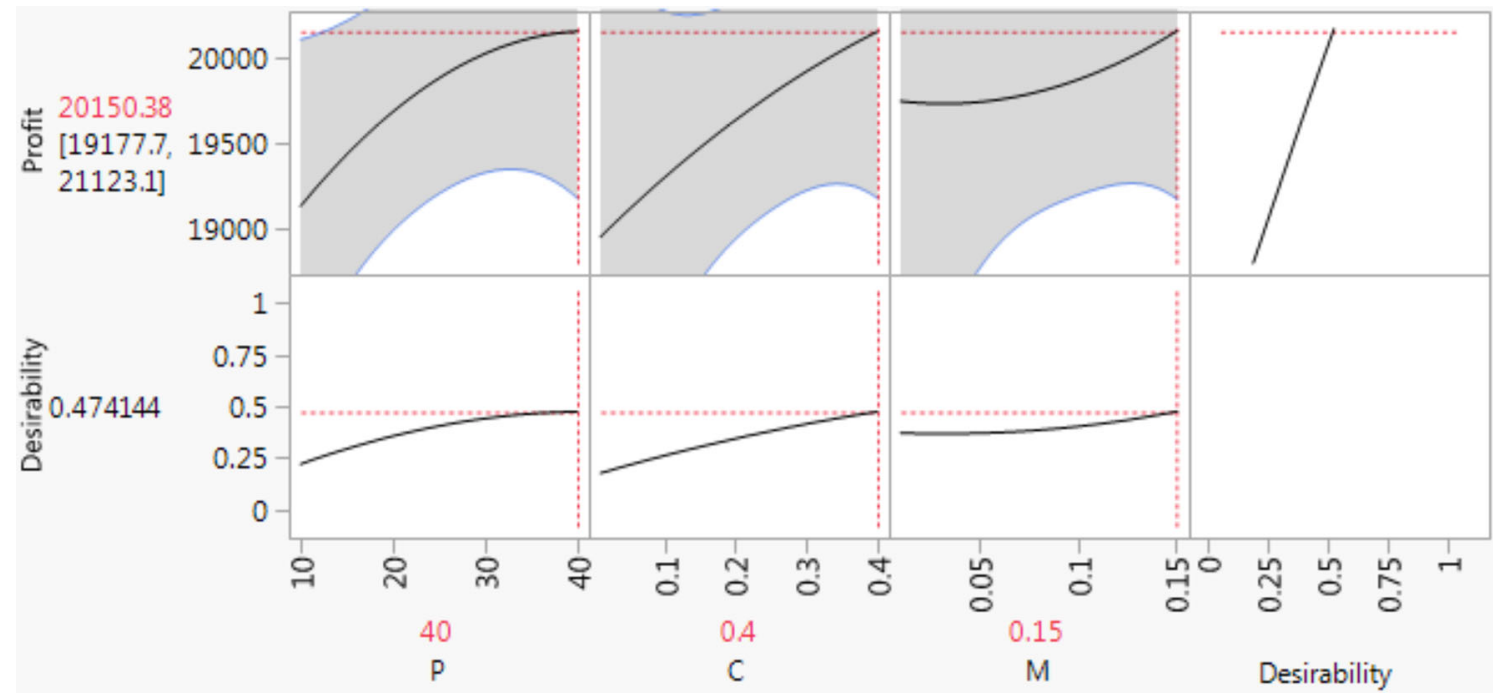

Figure 5. Prediction profiler and maximum desirability using the Box-Behnken design.

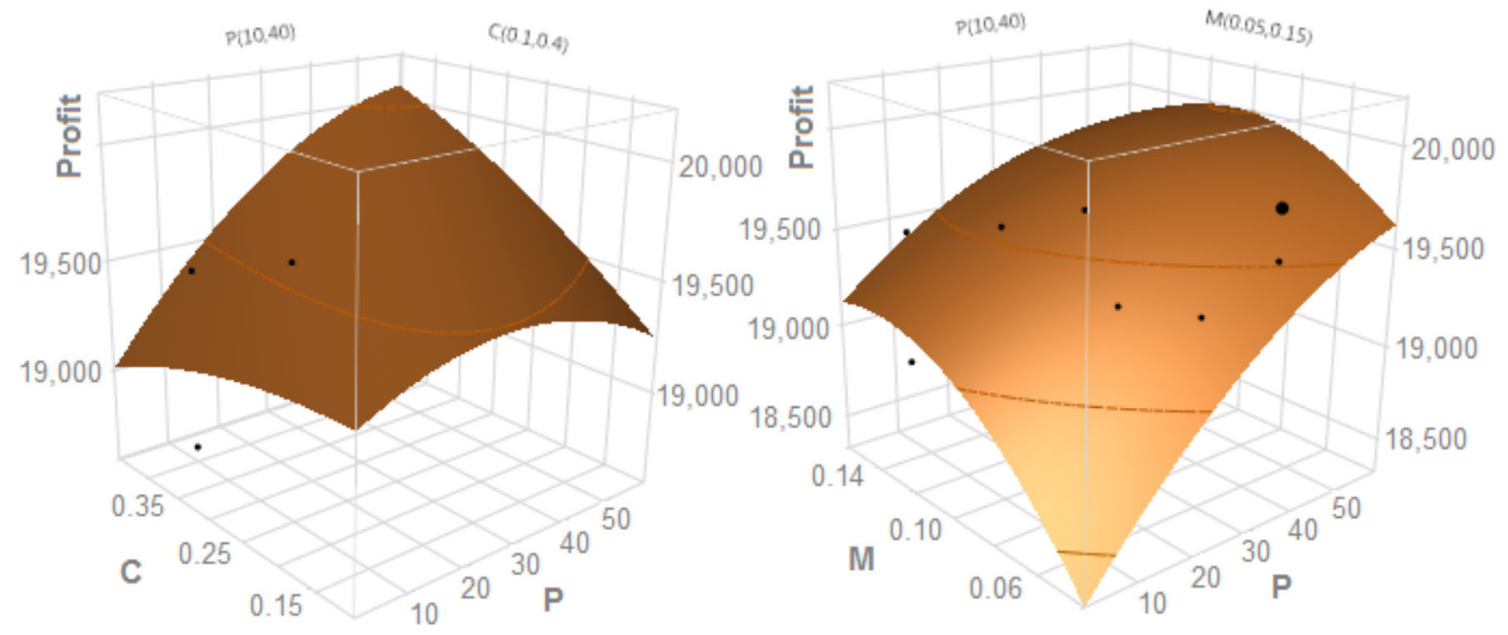

Figure 6. The surface of regression model using Box-Wilson design in RSM. 